\title{
TRABALHO E RENDIMENTOS NA NOVA SÉRIE DO SISTEMA DE CONTAS NACIONAIS*
}

\author{
João Hallak Neto ${ }^{* *}$
}

\author{
Luciene Rodrigues Kozovits ${ }^{* *}$
}

Roberto Luis Olinto Ramos ${ }^{* * * *}$

\section{Sandra Rosa Pereira}

RESUMO Este artigo tem como objetivo comparar os resultados do fator trabalho e dos rendimentos a ele associados entre as séries antiga e nova do SCN do Brasil. Assim, foram apresentados os principais aspectos conceituais e metodológicos e as diferenças existentes na construção e nos resultados obtidos pelas duas séries do SCN. Para avaliar os novos resultados, eles foram comparados com os dados de outras bases estatísticas freqüentemente utilizadas nos estudos relativos ao mercado de trabalho: PNAD, POF e Rais. O confronto dos resultados do SCN com os das bases selecionadas ratificaram a conclusão de que essas variáveis estão mais bem mensuradas na nova série do SCN, e que se encontravam subestimadas nos anos finais da série antiga.

* Artigo recebido em 5 de setembro de 2007 e aprovado em 28 de agosto de 2008. Os autores agradecem as sugestões e comentários de Danielle Machado. As conclusões, erros e omissões são, todavia, de inteira responsabilidade dos autores.

** Gerente de renda e emprego da Coordenação de Contas Nacionais do IBGE, e-mail: joao.hallak@ ibge.gov.br

*** Analista de renda e emprego da Coordenação de Contas Nacionais do IBGE, e-mail: luciene.kozovits@ibge.gov.br

**** Chefe da Coordenação de Contas Nacionais do IBGE, e-mail: roberto.olinto@ibge.gov.br

***** Analista de renda e emprego da Coordenação de Contas Nacionais do IBGE, e-mail: sandra.pereira@ibge.gov.br 
Palavras-chave: trabalho; ocupações; rendimento; sistema de contas nacionais Código JEL: E24

\title{
LABOR AND INCOMES ON NEW SERIES OF BRAZILIAN NATIONAL ACCOUNT
}

\begin{abstract}
The objective of this article is to compare the results of labour factor and its associated income between the previous and the new series of the Brazilian SCN. Therefore, the main conceptual and methodological aspects and the existing differences in development and in the results of the two SCN series were presented. To evaluate the new results, they were compared to other statistical databases usually referred to in most labour market studies. The SCN results compared to PNAD, POF and Rais proved that these variables are more reliable in the new SCN series and that they were subestimated in the last years of the previous series.
\end{abstract}

Key words: labor; jobs; income; system of national account 


\section{INTRODUÇÃO}

O Instituto Brasileiro de Geografia e Estatística (IBGE) divulgou, em março de 2007, os resultados da nova série do Sistema de Contas Nacionais (SCN), que tem como referência o ano 2000. A principal alteração em relação à série antiga foi a introdução de novas bases estatísticas que possibilitam a existência de marcos estruturais anuais para os resultados do sistema. A incorporação de resultados de novas pesquisas do IBGE, como o Censo Agropecuário, as pesquisas econômicas anuais nas áreas de Indústria, Construção Civil, Comércio e Serviços, e de pesquisas domiciliares, como a Pesquisa de Orçamentos Familiares (POF) 2002-2003 e a Pesquisa Nacional por Amostra de Domicílios (PNAD), bem como de informações anuais de outras instituições, como a Declaração de Informações Econômico-fiscais da Pessoa Jurídica (DIPJ) obtidas pela Secretaria da Receita Federal, além dos balanços fornecidos pelas Agências Reguladoras, reforçam a qualidade do sistema para os anos correntes.

Outra consideração a respeito das mudanças incorporadas ao SCN refere-se à atualização de conceitos e definições em conformidade com as últimas recomendações dos organismos internacionais. ${ }^{1}$ Adicionalmente, a adoção de uma nova classificação de atividades econômicas, compatível com a versão 1.0 da Classificação Nacional de Atividades Econômicas (CNAE), facilitou a integração das bases de dados com o sistema e permitiu uma maior abertura de atividades e produtos. A partir dessa nova classificação, a divulgação do SCN passa a ser realizada para 55 atividades e 110 grupos de produtos contra 43 atividades e 80 grupos de produtos da referência anterior.

A série do SCN vigente até março de 2007 teve como referência o ano $1985^{2}$ e dispõe de resultados para as Tabelas de Recursos e Usos (TRU) no período de 1990 a 2003, com as informações sobre a origem e o destino dos bens e serviços gerados na economia brasileira detalhadas por atividade econômica e por produto, medidas a preços correntes e a preços do ano anterior. Os anos 2004 e 2005 possuem resultados preliminares, obtidos pelo Sistema de Contas Trimestrais, que contém um menor detalhamento de atividades e produtos, além de não apresentar a composição do PIB pela ótica da renda. 
A experiência internacional mostra que mudanças de série para o Sistema de Contas Nacionais usualmente trazem um considerável número de alterações em relação aos resultados até então apresentados. No caso brasileiro, a nova série do SCN introduzida em 2007 pelo IBGE provocou modificações nos componentes do PIB que podem ser notadas nas três óticas de mensuração. Pelo lado da produção, verificou-se uma redefinição do peso das atividades econômicas em relação ao PIB, em que cabe destacar o aumento no grupo serviços e as perdas relativas da agropecuária e da construção civil. Pela ótica da despesa, ressaltam-se a queda da formação bruta de capital fixo em proporção ao PIB e o aumento do consumo das famílias. Finalmente, na conta da renda os impactos mais significativos foram o crescimento, tanto em termos absolutos quanto relativos dos rendimentos associados ao trabalho, e a conseqüente redução da parcela correspondente ao excedente operacional bruto. ${ }^{3}$

O objetivo deste texto é comparar os resultados relacionados ao fator trabalho (ocupação e rendimento) da nova série com os da série antiga, propondo uma primeira reflexão sobre o tema. $\mathrm{O}$ marco selecionado para essa análise foi 2003, o último ano em que foram divulgados os resultados completos das contas nacionais na série com referência em 1985.

Os diferenciais observados tanto nos dados de ocupação quanto nos de rendimento do trabalho entre as duas séries motivaram uma avaliação mais acurada, impondo, por sua vez, uma comparação dos resultados do SCN com os de outras fontes estatísticas. Nesse sentido, utilizamos as informações de duas reconhecidas pesquisas domiciliares do IBGE (a PNAD e a POF) e os registros censitários da Relação Anual de Informações Sociais (Rais) do Ministério do Trabalho e Emprego.

O texto inicia-se com uma breve apresentação das metodologias aplicadas para obtenção das variáveis do fator trabalho e do rendimento nas duas séries referidas. $\mathrm{O}$ confronto dos resultados de ocupação e rendimento entre as séries antiga e nova encontra-se na seção 2. A seção 3 destina-se à comparação dos dados das séries do SCN com os das demais fontes estatísticas, com a finalidade de subsidiar a análise da qualidade dos novos resultados do SCN. Por fim, as considerações finais compõem a seção 4. 


\section{SÍNTESE DAS METODOLOGIAS: MENSURAÇÃO DO FATOR TRABALHO}

\subsection{Série antiga do SCN: referência 1985}

O IBGE apresentou os resultados das contas nacionais entre 1997 e 2005, tendo como marco de referência o ano 1985. Tais resultados foram estimados de acordo com as novas recomendações das Nações Unidas, expressas no Manual de Contas Nacionais de 1993 (ONU, 2007). ${ }^{4}$

O trabalho de definição das estimativas do número de pessoal ocupado e de seus respectivos rendimentos para o ano-base teve início com a investigação de fontes básicas e, conseqüentemente, com as escolhas daquelas que seriam utilizadas em cada atividade.

No ano 1985, as fontes de informação selecionadas foram os Censos Econômicos (Industrial, Comercial, da Construção, dos Transportes e dos Serviços), o Censo Agropecuário de 1985, a Pesquisa Nacional por Amostra de Domicílio (PNAD) de 1985 e 1990 e a Declaração de Informações Econômico-fiscais da Pessoa Jurídica (DIPJ) de 1985 (IBGE, 2004). Dependendo da atividade e posição na ocupação, foram adotadas as informações de uma das fontes ou o resultante de um ajuste entre elas.

A partir do marco inicial do ano-base, os agregados de pessoas ocupadas e rendimentos foram evoluídos a cada ano, seja por extrapolação ou por deflação, pela aplicação de índices de variação do pessoal ocupado (índice de volume) e do rendimento médio (índice de preço) aos dados do ano anterior. As fontes básicas adotadas para a obtenção desses índices foram a PNAD, a Pesquisa Industrial Mensal — Dados Gerais - PIM-DG e o Cadastro de Empregadores da Relação Anual das Informações Sociais - Rais, sendo as duas últimas aplicadas somente ao setor formal da economia (IBGE, 2004). Para o caso particular dos trabalhadores por conta própria e dos assalariados sem carteira assinada, a evolução foi feita, na maior parte das vezes, ${ }^{5}$ com base na PNAD.

Algumas atividades específicas tiveram valores correntes para as variáveis de pessoas ocupadas e rendimento do trabalho. Por exemplo, nas atividades de serviços industriais de utilidade pública, comunicações e administração pública, os rendimentos foram informados pelas pesquisas Estatísticas Econômicas das Empresas Públicas e Estatísticas Econômicas das Administrações Públicas (ambas realizadas pela Coordenação de Contas Nacionais, 
do IBGE). Da mesma forma, as remunerações dos empregados em instituições financeiras procederam do Banco Central do Brasil. Os resultados das demais atividades foram alcançados pela evolução a partir do ano de referência da série, conforme descrito no parágrafo anterior.

Os resultados da evolução do pessoal ocupado nos anos correntes na série de 1985 não foram idênticos aos da estimativa apurada ano a ano pela PNAD. A razão do descolamento desses valores está associada ao viés causado pela utilização de índices de volume em um longo período. Essa mesma rotina foi aplicada, utilizando-se índices de preço, para a evolução das remunerações, o que contribuiu para a subestimação dessas variáveis, sobretudo nos anos finais da série. Em relação à população ocupada, em 1990, o resultado obtido na série antiga do $\mathrm{SCN}$ foi apenas $1,8 \%$ inferior à estimativa da PNAD. Conforme pode ser observado no gráfico 1, a diferença se acentuou até 1995, período de alta inflação, e alcançou 15,0\% 13 anos após, em 2003.

Para a melhor compreensão desse fenômeno, é importante notar que tanto o valor bruto da produção quanto o consumo intermediário, na maior parte das atividades, também foram suscetíveis às distorções ocasionadas pela utilização de índices de volume, e principalmente de preços, em perío-

Gráfico 1: Evolução das pessoas ocupadas na série antiga do SCN e na PNAD, 1990-2003

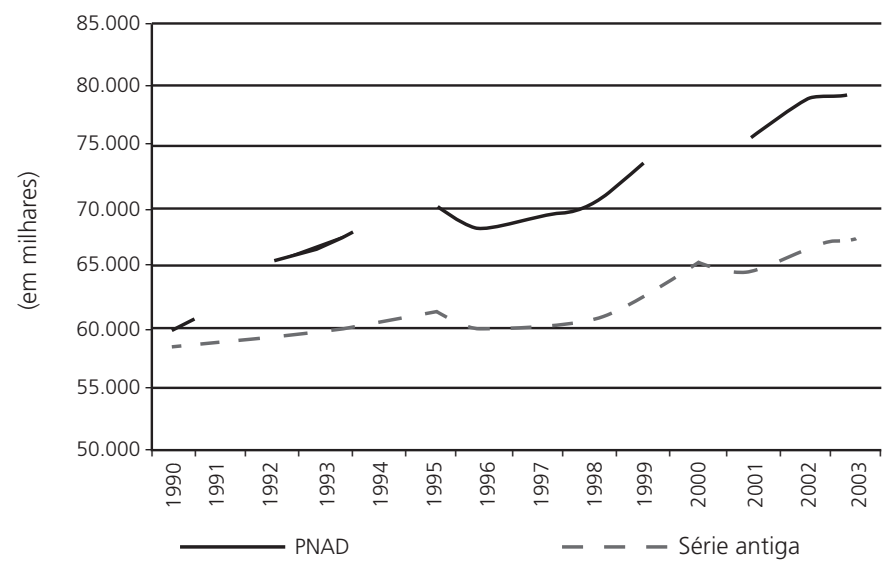

Nota: Nos anos 1991, 1994 e 2000 a PNAD não foi a campo.

Fonte: Elaboração própria a partir dos dados da série antiga do SCN/IBGE e da PNAD/IBGE. 
dos longos e de alta inflação. Assim, o valor adicionado (obtido pela diferença entre o valor da produção e o consumo intermediário) e seus componentes, dentre eles o rendimento do trabalho, sofreram os maiores impactos, que se refletiram também no cálculo dos rendimentos médios e da população ocupada.

\subsection{Nova série do SCN: referência $2000^{6}$}

Dentre as alterações metodológicas da nova série do SCN, duas questões merecem destaque: uma de natureza conceitual e outra relacionada às fontes de dados. A primeira refere-se à mensuração do fator trabalho no $\mathrm{SCN}$, que passou a ser representado pelo número de ocupações (ou postos de trabalho) em vez de população ocupada. Nesse sentido, dado que uma mesma pessoa pode ter mais de uma ocupação, seu número é necessariamente superior ao de pessoas ocupadas. Assim, para incorporar os resultados de levantamentos realizados por estatísticas domiciliares, foram considerados o trabalho principal e o trabalho secundário da pessoa ocupada. ${ }^{7}$

A outra questão destacada diz respeito à inclusão das pesquisas econômicas estruturais do $\mathrm{IBGE}^{8}$ e dos registros administrativos provenientes da DIPJ no Sistema de Contas Nacionais. Essas bases estatísticas passaram a alimentar o sistema com as informações sobre as ocupações com vínculo e suas respectivas remunerações. Além dessas, outras fontes foram utilizadas para o cálculo das ocupações e remunerações de atividades específicas, ${ }^{9}$ como a PNAD, o Cadastro Central de Empresas do IBGE - Cempre e os dados da Agência Nacional de Energia Elétrica - Aneel. As informações relativas aos rendimentos enviados e recebidos do exterior carregados no SCN foram obtidas no Balanço de Pagamentos divulgado pelo Banco Central, enquanto os dados de rendimento do setor público da economia advêm da Pesquisa Administração Pública do IBGE.

A PNAD é utilizada como base anual para a obtenção das ocupações sem vínculo, de trabalhadores por conta própria e empregadores do setor institucional famílias (empregadores informais) ${ }^{10}$ e dos trabalhadores não remunerados, bem como fornece as estimativas da massa de salário dos empregados sem vínculo e dos rendimentos dos trabalhadores por conta própria e empregadores informais.

A utilização da estimativa do número total de ocupações da PNAD como referência na nova série do $\mathrm{SCN}$ levou em conta a sua periodicidade e abran- 
Gráfico 2: Evolução das ocupações na nova série do SCN e na PNAD, 1995-2004

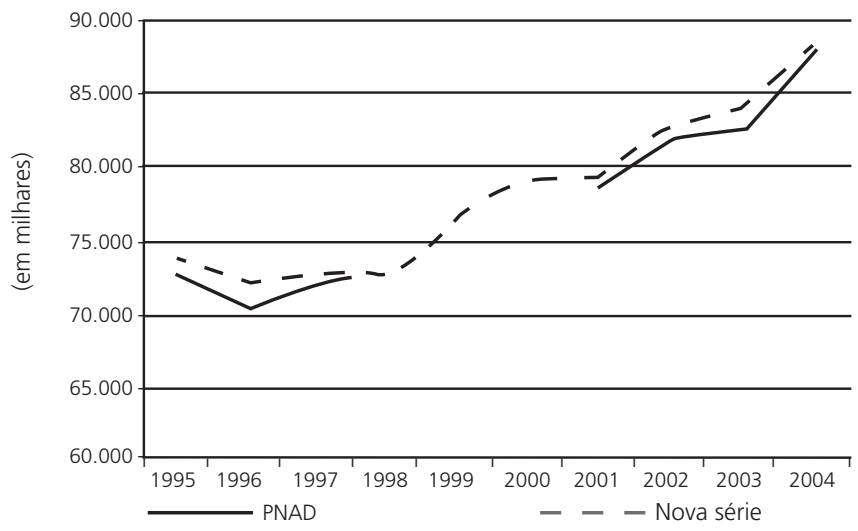

Nota: No ano 2000 a PNAD não foi a campo.

Fonte: Elaboração própria a partir dos dados da série antiga do SCN/IBGE e da PNAD/IBGE.

gência geográfica, evitando o surgimento de grandes diferenças ao longo da série. Ademais, a PNAD é reconhecida pela produção de um conjunto de informações de grande importância e qualidade para o acompanhamento sistemático da evolução do trabalho e do rendimento no Brasil. O total de ocupações da PNAD tende a ser muito próximo do total de ocupações da nova série que representa a contribuição do fator trabalho para a produção calculada pelo SCN (gráfico 2).

O tratamento do rendimento do trabalho no SCN não admitiu o dado estimado pela PNAD como referência estrita, uma vez que a pesquisa foi adotada apenas para o cálculo do rendimento das ocupações que não foram consideradas pelas pesquisas econômicas ou pelos registros administrativos utilizados. Nesse sentido, o rendimento total final é resultado da interação entre diversas fontes e do trabalho de arbitragem realizado no processo de descentralização do sistema, podendo, portanto, apresentar-se afastado do informado pela PNAD. Vale lembrar que as informações de rendimentos brutos fornecidas pelo empregador, como é o caso das pesquisas estruturais e dos registros administrativos em que é possível se consultar os registros contábeis, são mais precisas do que as obtidas pelas entrevistas domiciliares. 


\section{COMPARANDO AS SÉRIES DE 1985 E DE 2000 DO SCN}

De acordo com a metodologia da nova série do SCN, exposta na seção anterior, a principal diferença entre as séries diz respeito à utilização dos dados das pesquisas econômicas anuais do IBGE. Para o SCN com referência em 2000, esse novo conjunto de dados representa mais qualidade na informação no ano-base, bem como permite ajustes sistemáticos na medida em que seus resultados vão sendo incorporados aos anos correntes, evitando as distorções geradas pelo uso continuado de indicadores de volume e preço sem a referência estrutural. A outra diferença mencionada, também com reflexos nos resultados, é a mensuração do fator trabalho por intermédio do total de ocupações em vez da população ocupada.

As diferenças dos resultados divulgados para o ano 2003 da série antiga e dos obtidos na nova série do SCN são consideráveis tanto em relação ao número de empregos quanto à massa de rendimentos, aqui definida como a soma dos salários brutos e do total do rendimento misto bruto. ${ }^{11}$

Examinando inicialmente a estimativa da ocupação, a série com referência em 1985 tem como resultado 67,3 milhões de pessoas ocupadas. A nova série apresenta aproximadamente 84,0 milhões de ocupações, que, conforme a metodologia utilizada, corresponde à soma dos trabalhos principal e secundário das pessoas ocupadas. O aumento entre o total de ocupações na nova série e o pessoal ocupado na série de 1985 equivaleu, portanto, a 24,8\% (tabela 1).

Para se ter idéia da magnitude do impacto da introdução de novas bases estatísticas no sistema, de forma isolada, considerou-se a comparação do indicador de população ocupada nas duas séries. Assim, o número de pes-

Tabela 1: Ocupação e rendimentos nas séries antiga e nova do SCN, 2003

\begin{tabular}{|c|c|c|c|}
\hline & Série antiga (a) & Nova série $(b)$ & "Diferença (\%) (b) / (a)" \\
\hline Pessoa ocupada (em milhares) & 67.334 & 79.833 & 18,6 \\
\hline Ocupações (em milhares) & nd & 84.035 & $24,8^{*}$ \\
\hline Massa de rendimento ( $R \$$ milhões) & 469.639 & 708.233 & 50,8 \\
\hline Massa de salário** & 399.882 & 528.173 & 32,1 \\
\hline Rendimento misto & 69.757 & 180.060 & 158,1 \\
\hline Rendimento médio ( $\mathrm{R} \$$ ) & 6.975 & 8.871 & 27,2 \\
\hline \multicolumn{4}{|l|}{ nd: não disponível } \\
\hline \multicolumn{4}{|c|}{ * Em relação ao total de pessoas ocupadas estimado na série com referência em 1985.} \\
\hline \multicolumn{4}{|c|}{ ** Inclui salários das ocupações com e sem vínculo. } \\
\hline \multicolumn{4}{|c|}{ Fonte: Elaboração própria a partir do SCN/IBGE. } \\
\hline
\end{tabular}


soas ocupadas na nova série foi estimado excluindo-se do total de ocupações apurado pelo SCN 2000 a parcela dos que possuíam mais de um trabalho, conforme a PNAD 2003. ${ }^{12}$ Nessa hipótese, a diferença decresceria para $18,6 \%$, o que representa 12,5 milhões de pessoas ocupadas a mais na nova série (67,3 milhões contra 79,8 milhões).

Ao se comparar o dado de salário na série antiga do SCN com o da nova série, verifica-se que, em 2003, o total de salários na primeira alcançou R \$ 399,9 bilhões. O resultado desse mesmo agregado na nova série foi equivalente a R\$528,2 bilhões, portanto superior em 32,1\%. Quando se incorpora a esse agregado o rendimento misto, tais valores passam de $\mathrm{R} \$ 469,6$ na série antiga para e $\mathrm{R} \$ 708,2$ bilhões na nova, expressando um aumento de 50,8\% nessa variável agregada.

Ressalta-se a significativa elevação dos rendimentos mistos na comparação entre as séries, que passou a representar 31,6\% da massa de rendimentos na nova série contra $14,9 \%$ na série de 1985 . Esse resultado, em parte, é explicado pela inclusão dos rendimentos dos empregadores informais no cálculo do rendimento misto na nova série. Outro fator a justificar a diferença relaciona-se ao maior rigor na captação do rendimento e da ocupação de trabalhadores por conta própria e de empregadores informais também promovida pela revisão do sistema, que afetou particularmente as variáveis relacionadas a essas categorias ocupacionais, tidas como mais vulneráveis à subestimação decorrente da extrapolação pelos índices de volume e preço na série antiga.

Os resultados apresentados revelam que a variação da massa de rendimentos, ou seja, do total de salários mais o rendimento misto, é superior à da população ocupada. Como o rendimento médio anual por pessoa ocupada na nova série ( $R$ \$ 8.871) supera em $27,2 \%$ o estimado na antiga ( $R$ \$ 6.975), a elevação de 50,8\% apurada na massa de rendimentos pode ser decomposta da seguinte maneira: $18,6 \%$ referem-se ao aumento dos ocupados e $27,2 \%$, do rendimento médio por pessoa ocupada. Os dados encontramse na tabela 1 .

\section{AVALIANDO OS RESULTADOS DA SÉRIE 2000}

Qualquer iniciativa de análise dos resultados de trabalho e rendimento da nova série do SCN pressupõe a sua comparação com outras fontes estatísti- 
cas. A escolha das bases de comparação levou em conta a possibilidade de compatibilização dos conceitos e a cobertura territorial. Por esses critérios, foram selecionadas duas das principais pesquisas domiciliares do país: a PNAD e a POF. Além dessas fontes, consideramos as informações da Rais que, no entanto, restringem-se ao universo formal do emprego. A comparação com os dados da DIPJ foi descartada devido à impossibilidade da obtenção de resultados satisfatórios para a remuneração das empresas que declararam o formulário destinado às imunes/isentas e o Simples. ${ }^{13}$

A ampla utilização dessas pesquisas nos estudos sobre mercado de trabalho, nos casos da PNAD e da Rais, e sobre renda e consumo, no caso da POF, referenda as suas indicações para a análise proposta. A PNAD é a principal referência do $\mathrm{SCN}$ para o total de ocupações e fornece os dados relativos às remunerações dos empregados sem carteira assinada e dos trabalhadores por conta própria. A Rais, por sua vez, é um instrumento usual entre diversos pesquisadores e instituições nas avaliações do mercado formal de trabalho.

A exemplo do que foi realizado na seção 2, destinada à comparação entre as séries antiga e nova do $\mathrm{SCN}$, é necessário que as diferenças conceituais sejam minimizadas para a análise dos dados do SCN vis-à-vis aqueles estimados pelas demais fontes indicadas. Dessa forma, para cada variável selecionada apresentamos, a seguir, uma discussão a respeito dessas diferenças, fundamentando os ajustes realizados para aperfeiçoar a comparação entre as bases escolhidas.

\subsection{Comparação: SCN e PNAD}

A análise desta subseção está amparada nos dados de ocupação e rendimento da PNAD de 2003 que diferem dos agregados contemplados no SCN em uma série de aspectos. O primeiro deles corresponde ao período de referência da pesquisa. Na PNAD, esse período é o mês de setembro. Assim, para que as suas informações sejam comparáveis às do SCN é necessário harmonizar os valores monetários das bases, convertendo o rendimento apurado pela pesquisa em seu equivalente anual. ${ }^{14}$

Um outro ponto é que na PNAD de 2003 as estatísticas apresentadas para a totalidade do país não incluem a área rural da região Norte. Os dados, no entanto, não sofreram nenhum tratamento de conciliação em função desse quesito, tendo em vista a reduzida representatividade dessa área no que se refere às estimativas de ocupações e rendimentos. ${ }^{15}$ 
Uma última observação refere-se às divergências conceituais. Na PNAD, são classificadas como ocupadas na semana de referência ${ }^{16}$ as pessoas que tinham trabalho ${ }^{17}$ durante todo ou parte desse período. Como a nova metodologia do SCN passou a empregar o conceito de postos de trabalho ou ocupações, a mudança determinou o ajuste na estimativa de população ocupada fornecido pela pesquisa, acrescentando-se ao trabalho principal o trabalho secundário das pessoas que possuíam mais de uma ocupação na semana de referência. ${ }^{18}$

Em relação à análise da massa salarial, a PNAD admite como rendimento mensal de trabalho para empregados a remuneração bruta mensal a que normalmente teriam direito trabalhando o mês completo ou, no caso de rendimento variável, a remuneração média mensal referente ao mês de setembro. A pesquisa considera remuneração bruta, por seu turno, o pagamento da remuneração sem excluir o salário-família e os descontos relativos aos pagamentos de instituto de previdência, imposto de renda, faltas etc., e não inclui o décimo terceiro e a participação nos lucros, bem como a parcela recebida em benefícios (moradia, alimentação, roupas, vales-refeição, alimentação ou transporte, entre outros). No SCN, a estimativa de rendimento do trabalho de empregados é entendida como o somatório dos ordenados e salários brutos dos empregados, incluindo benefícios trabalhistas e outros rendimentos eventuais. Assim, esse agregado no SCN difere do dado da PNAD porque contempla em seu cálculo os benefícios trabalhistas e os rendimentos eventuais.

Existe ainda uma outra diferença conceitual, relacionada às definições de empregador e trabalhador por conta própria, que requer uma atenção espe-

Tabela 2: Comparação de ocupação e rendimentos: séries do SCN e PNAD - 2003

\begin{tabular}{|c|c|c|c|c|c|}
\hline & \multicolumn{3}{|c|}{ Total } & \multicolumn{2}{|c|}{ Diferença (\%) } \\
\hline & $\begin{array}{l}\text { SCN } 1985 \\
\text { (a) }\end{array}$ & $\begin{array}{l}\text { SCN } 2000 \\
\text { (b) }\end{array}$ & $\begin{array}{l}\text { PNAD } \\
\text { (c) }\end{array}$ & (a) / (c) & (b) / (c) \\
\hline Ocupação (em milhares) & nd & 84.035 & 82.463 & nd & $1,9 \%$ \\
\hline Pessoal ocupado (em milhares) & 67.334 & 79.833 & 79.251 & $-15,0 \%$ & $0,7 \%$ \\
\hline Massa de rendimento ( $\mathrm{R} \$$ milhões) & 469.639 & 708.233 & 599.771 & $-21,7 \%$ & $18,1 \%$ \\
\hline Massa de salário* & 399.882 & 528.173 & 385.955 & $3,6 \%$ & $36,8 \%$ \\
\hline Rendimento misto & 69.757 & 180.060 & 213.816 & $-67,4 \%$ & $-15,8 \%$ \\
\hline
\end{tabular}


cial para a comparação dos resultados desagregados entre as bases. No SCN, o rendimento do empregador e do trabalhador por conta própria equivale ao rendimento misto recebido pelos proprietários de unidades produtivas não constituídas em sociedade, com ou sem empregados (empregador e trabalhador por conta-própria, respectivamente). Caso a unidade produtiva seja formalmente constituída, o entendimento no SCN é que esses trabalhadores são empregados com vínculo das empresas. ${ }^{19}$ Para a PNAD, o empregador e o trabalhador por conta-própria também são definidos como pessoas que trabalham explorando o seu próprio empreendimento, com ou sem empregados, porém, tal empreendimento pode ser ou não formalmente constituído. Isso significa que uma proporção dos rendimentos de empregadores e trabalhadores por conta própria, computados pela pesquisa domiciliar, não consta da estimativa de rendimento misto do SCN, sendo, entretanto, contabilizada na massa de salário. ${ }^{20}$

A análise dos dados da tabela 2 identifica, primeiramente, o impacto das mudanças conceituais e metodológicas implementadas pelo Sistema de Contas Nacionais no total de ocupações divulgado pelo SCN de 2000. Enquanto o total de pessoas ocupadas, indicador utilizado na série de 1985, apresentou-se $15,0 \%$ inferior ao dado estimado pela PNAD, o total de postos de trabalho, gerado em 2003 pela nova metodologia, mostrou-se muito próximo ao dado da PNAD. ${ }^{21}$

Se, por um lado, era esperado que a estimativa do fator trabalho na nova série do $\mathrm{SCN}$ se apresentasse aderente à da PNAD, não somente em função da metodologia adotada, mas também pelo fato de ser uma fonte reconhecida internacionalmente por sua qualidade em relação à mensuração do universo do trabalho, por outro lado, o mesmo não se poderia afirmar, a priori, em relação à massa de rendimento. Com efeito, no SCN a obtenção desta variável envolve a agregação de resultados obtidos por diversas fontes, dentre as quais se destacam as pesquisas econômicas do IBGE. Assim, observando os resultados relativos à massa de rendimento é possível identificar que o aumento de 50,8\% assinalado nesse agregado entre uma série e outra permitiu que a estimativa alcançasse o patamar de $\mathrm{R} \$ 708,2$ bilhões que, se confrontada à da PNAD ( $\mathrm{R}$ \$ 599,7 bilhões), indica uma diferença de 18,1\% (tabela 2).

A despeito do expressivo crescimento dos rendimentos mistos na comparação entre as séries, observado na seção 2, é importante destacar que a 
variação da massa salarial ${ }^{22}$ responde em grande medida pelo resultado da massa de rendimento, dada a sua representatividade na composição do agregado (74,6\%). O total de salários das ocupações com e sem vínculo apresentado na nova série do SCN, estimado em R $\$ 528,2$ bilhões, supera em $36,8 \%$ o dado da PNAD.

A magnitude do resultado superior dos salários computados pelo SCN está de acordo com o esperado. Conforme citado anteriormente, a discrepância entre os dados está associada aos benefícios e outros rendimentos eventuais, não incluídos pela PNAD, e à diferença entre as duas bases no que diz respeito ao significado de empregador e trabalhador por conta-própria apontada nesta seção. Tal diferença contribui para justificar o dado de rendimento misto apurado pelo SCN de 2000 (R\$ 180,1 bilhões), inferior em 15,8\% à estimativa da PNAD (R\$213,8 bilhões). Ademais, há de se considerar as indicações de que o rendimento captado por pesquisas domiciliares sofre mais efeitos de subestimação ${ }^{23}$ que o apurado no SCN devido à própria natureza do levantamento.

\subsection{Comparação: SCN e POF}

A POF é uma pesquisa específica sobre as estruturas de consumo, gasto e renda das famílias; conseqüentemente, a presente análise se restringirá à comparação das estimativas de rendimento.

O confronto dos dados do SCN e da POF exige o exame de duas questões importantes. Em primeiro lugar está o fato de que os rendimentos e as informações relacionadas são coletados pela POF segundo o período de referência de 12 meses. Todavia, a pesquisa conta com uma data referencial para apresentação dos resultados. ${ }^{24} \mathrm{Na}$ POF de 2002-2003 essa data correspondeu a 15 de janeiro de 2003. Sendo assim, os seus resultados foram anuali-

Tabela 3: Comparação dos rendimentos, séries do SCN e POF - 2003

\begin{tabular}{lccccc}
\hline & \multicolumn{3}{c}{ Total } & \multicolumn{2}{c}{ Diferença (\%) } \\
\cline { 2 - 6 } & $\begin{array}{c}\text { SCN 1985 } \\
\text { (a) }\end{array}$ & $\begin{array}{c}\text { SCN 2000 } \\
\text { (b) }\end{array}$ & $\begin{array}{c}\text { POF } \\
\text { (c) }\end{array}$ & (a) / (c) & (b) / (c) \\
\hline Massa de rendimento (em R\$ milhões) & 469.639 & 708.233 & 699.348 & $-32,8 \%$ & $1.3 \%$ \\
\hline Massa de salário* & 399.882 & 528.173 & 478.875 & $-16,5 \%$ & $10,3 \%$ \\
\hline Rendimento misto & 69.757 & 180.060 & 220.472 & $-68,4 \%$ & $-18,3 \%$ \\
\hline *Inclui salários das ocupações com e sem vínculo. & & & & \\
Fonte: Elaboração própria a partir do SCN/BGE e da PNAD/BGE. & & & &
\end{tabular}


zados e corrigidos pelo Índice Nacional de Preços ao Consumidor (INPC) de 2003.

Outra questão diz respeito ao fato de que, dentre as pesquisas domiciliares, a POF é tradicionalmente reconhecida por sua maior capacidade de captar a renda das famílias. No que concerne ao cálculo do rendimento do empregado, por exemplo, isso é nítido, pois a pesquisa inclui outros tipos de rendimentos não contemplados pela PNAD. ${ }^{25}$ Assim, presume-se que a estimativa obtida para massa total de rendimento do trabalho, a partir dos dados dessa pesquisa, seja bem semelhante ao agregado divulgado pelo SCN. Contudo, a análise dos resultados desagregada segundo as categorias ocupacionais selecionadas deve levar em consideração a mesma discrepância entre os conceitos de empregador e trabalhador por conta própria, descrita na subseção anterior, sendo justificada a existência de eventuais diferenças. Os dados da tabela 3 sustentam essa dedução.

A massa de rendimento da nova série do $\mathrm{SCN}$ foi maior em relação à estimada para a POF em apenas 1,3\%, enquanto as diferenças na massa salarial e no rendimento misto foram mais expressivas. $\mathrm{O}$ dado de remuneração de empregados na nova série superou o da pesquisa domiciliar em 10,3\%. Já o rendimento misto foi inferior em 18,3\% ao da POF. Essa diferença entre os componentes da massa de rendimento é explicada pela contabilização, no SCN, dos rendimentos dos empregadores formais como salários e não como rendimento misto, conforme a metodologia recomendada para as contas nacionais.

\subsection{Comparação: SCN e Rais/MTE}

A Rais investiga o mercado formal de trabalho brasileiro e tem cobertura de cerca de 97\% do universo dos estabelecimentos do território nacional. Estão contemplados nas declarações da Rais os empregados contratados sob o regime da CLT; os servidores da administração pública; os trabalhadores temporários, bem como aqueles com contrato de trabalho por prazo determinado; os diretores sem vínculo empregatício, para os quais o estabelecimento ou entidade tenha optado pelo recolhimento do FGTS; entre outros. ${ }^{26}$

Por intermédio da Rais é possível obter o número de empregos formais na data de referência do levantamento, ou seja, em 31 de dezembro de 2003, permitindo a comparação apenas com uma parcela do total da ocupação 
divulgado pelo SCN. O distinto período de referência, no caso da Rais (dezembro de 2003), contra a média do ano utilizado no SCN não constitui um grave problema, na medida em que a comparação dos resultados será realizada sem considerar a desagregação por atividades, que sofreria impactos sazonais. ${ }^{27}$ Entretanto, a viabilização dessa comparação requer a desagregação da estimativa do SCN por posição na ocupação, excluindo do total de ocupações divulgado, aquelas que dizem respeito aos empregados sem carteira de trabalho assinada, aos trabalhadores por conta própria e empregadores informais e aos trabalhadores não remunerados. O confronto será limitado à estimativa da nova série do $\mathrm{SCN}$, uma vez que o dado informado pela Rais é o número de ocupações e não o total de pessoas ocupadas apresentado na série antiga.

A tabela 4 revela o dado resultante do destaque das ocupações com vínculo do SCN assim como a estimativa de emprego formal obtida através da Rais.

A diferença de resultados para as ocupações com vínculo no SCN pode parecer significativa $(15,4 \%)$ no entanto, para entender melhor o fenômeno, deve-se considerar que no SCN, além dos empregados com carteira assinada e funcionários públicos, estão contabilizados também os sócios e proprietários envolvidos nas atividades das empresas formalmente constituídas, que são obtidos pelas pesquisas econômicas e que não estão contemplados nesse levantamento da Rais.

Desse modo, com a finalidade de aprimorar a comparação, foi necessário estimar o resultado das ocupações com vínculo para a Rais, harmonizado conforme a definição do $\mathrm{SCN}$, ou seja, incluindo os sócios ou proprietários das empresas formalmente constituídas. Para isso, consideraram-se inicialmente as participações relativas dessa categoria ocupacional de acordo com os setores de atividade informados pelas pesquisas econômicas do IBGE, para o ano 2003. Os dados que constam da tabela 5 indicam que 13,0\% do total das ocupações com vínculo estimado são de sócios ou proprietários e que sua presença é mais significativa no Comércio $(26,4 \%)$ e nos Serviços (19,3\%), seguida pelos setores da Construção Civil $(11,1 \%)$ e da Indústria de Transformação e Extrativa Mineral, ambas com proporções equivalentes a 3,7\%. ${ }^{28} \mathrm{O}$ total de ocupações da Rais harmonizado alcançou o patamar de 
Tabela 4: Comparação das ocupações: séries do SCN e Rais, 2003

\begin{tabular}{lc}
\hline & Ocupação com vínculo \\
\hline SCN 2000 (em milhares) & 34.103 \\
\hline Rais (em milhares) & 29.545 \\
\hline Diferença (\%) & $15,4 \%$ \\
\hline
\end{tabular}

Fonte: Elaboração própria a partir do SCN/IBGE e da PNAD/IBGE.

Tabela 5: Estimativa da ocupação com

vínculo para a Rais segundo o conceito do SCN, 2003

\begin{tabular}{lcccc}
\hline & $\begin{array}{c}\text { Ocupação } \\
\text { com vínculo } \\
\text { (Rais) }\end{array}$ & $\begin{array}{c}\text { Ocupação de sócios } \\
\text { ou proprietários } \\
\text { estimada }\end{array}$ & $\begin{array}{c}\text { Ocupação } \\
\text { com vínculo } \\
\text { harmonizada }\end{array}$ & $\begin{array}{c}\text { Ocupação } \\
\text { com vínculo } \\
\text { harmonizada }\end{array}$ \\
\hline Indústria extrativa mineral & 122.806 & 4.749 & 127.555 & 3,7 \\
\hline Indústria de transformação & 5.356 .159 & 207.136 & 5.563 .295 & 3,7 \\
\hline Serviços industriais de utilidade pública & 319.068 & -319.068 & - & 11,1 \\
\hline Construção civil & 1.048 .251 & 130.233 & 1.178 .484 & 26,4 \\
\hline Comércio & 5.119 .479 & 1.840 .790 & 6.960 .269 & 19,3 \\
\hline Serviços & 9.378 .566 & 2.247 .972 & 11.626 .538 & - \\
\hline Administração pública & 6.991 .973 & -6.991 .973 & - & 13,0 \\
\hline Agropecuária & 1.207 .672 & -1.207 .672 & & \\
\hline Total & 29.543 .974 & 4.430 .880 & 33.975 .807 & \\
\hline Fonte: Elaboração própria a partir das pesquisas econômicas do IBGE e da Rais/MTE. & &
\end{tabular}

33,9 milhões de empregos. Esse resultado, portanto, se comparado ao obtido no SCN (34,1 milhões), mostra que a diferença de $15,4 \%$ se reduz para apenas $0,4 \%$, ratificando a qualidade do dado de ocupação com vínculo da nova série do SCN.

\section{CONSIDERAÇÕES FINAIS}

Este estudo teve como objetivo analisar a discrepância dos resultados do fator trabalho e dos rendimentos a ele associados entre a séries antiga e nova do SCN para o ano 2003. De modo a fundamentar a análise comparativa proposta, foram apresentados os principais aspectos conceituais e metodológicos da construção de cada uma das séries, indicando as diferenças entre elas. Os resultados foram posteriormente comparados com os de outras bases estatísticas freqüentemente utilizadas nos estudos relativos ao mercado de trabalho. 
A comparação dos valores do ano 2003, evoluídos a partir da base de 1985, com os resultados do mesmo ano da nova série de contas nacionais mostrou diferenças significativas nos resultados agregados de ocupação e rendimentos e confirmou a noção de subestimação da população ocupada e rendimentos do trabalho na série antiga. Os resultados deste estudo indicaram que a maior contribuição para a diferença verificada na massa total de rendimento entre as séries $(50,8 \%)$ procede do crescimento do rendimento médio $(27,2 \%)$, enquanto a variação do fator trabalho responde por 18,6\% daquela diferença. Esse resultado, contudo, decorre basicamente da incorporação de novas fontes estatísticas para os anos correntes, bem como das mudanças conceituais em relação à ocupação, que garantiram mais precisão aos dados, promovendo mais qualidade ao sistema ao longo dos anos correntes.

Uma outra etapa do presente estudo foi a comparação entre os resultados de ocupações e rendimentos da nova série do SCN com duas das principais pesquisas domiciliares do país, a PNAD e a POF. A despeito das diferenças conceituais apontadas, os dados levantados pelo SCN, com referência em 2000, revelaram-se muito mais próximos daqueles registrados pelas pesquisas domiciliares do que os resultados da série antiga.

Diferentemente do observado em relação à série antiga do SCN, o número de ocupações, variável considerada para o fator trabalho na nova série do $\mathrm{SCN}$, tem ao longo da série histórica uma aderência significativa ao resultado mensurado pela PNAD. Na comparação com essa fonte, em 2003, a variável medida pelo SCN foi superior em apenas 1,9\%.

No caso da massa de rendimento, a variável obtida pelo novo SCN superou o conceito equivalente mensurado pela PNAD em 18,1\% em 2003. Já em relação à POF, pesquisa mais completa quanto à captação dessa variável, a diferença reduziu-se para 1,3\% nesse mesmo ano. A maior diferença em relação à PNAD era esperada, uma vez que em tal pesquisa não estão contemplados os benefícios trabalhistas e os rendimentos eventuais, como participação nos lucros e resultados, variáveis consideradas como rendimentos do trabalho tanto na POF quanto no SCN. Assim, o confronto dos resultados do SCN com os da PNAD e da POF corroborou a conclusão de que essas variáveis estão mais bem mensuradas na nova série do SCN e que, de fato, se encontravam subestimadas nos anos finais da série antiga. 


\section{Anexo: Quadro comparativo conceitual entre o SCN e as pesquisas domiciliares (PNAD/POF)}

\begin{tabular}{|c|c|c|}
\hline Referência/conceitos & $\mathrm{SCN}$ & PNAD/POF \\
\hline Data referencial & $\begin{array}{l}\text { A referência do SCN para as ocupações } \\
\text { é a média do ano. Para as variáveis de } \\
\text { remunerações é o total recebido no ano. }\end{array}$ & $\begin{array}{l}\text { A data referencial fixada para } \\
\text { apresentação dos resultados da } \\
\text { POF foi } 15 \text { de janeiro de } 2003 \text {. Para } \\
\text { a PNAD, a referência é o mês de } \\
\text { setembro do ano. }\end{array}$ \\
\hline Empregado & $\begin{array}{l}\text { Indivíduo que possui um acordo com a } \\
\text { empresa em que trabalha em troca de } \\
\text { uma remuneração em numerário ou em } \\
\text { espécie, podendo se inserir no mercado } \\
\text { de trabalho como empregado, com ou } \\
\text { sem carteira assinada, funcionário } \\
\text { público ou como sócio e propriétário } \\
\text { das empresas constituídas em sociedade. }\end{array}$ & $\begin{array}{l}\text { Indivíduo que trabalha para um } \\
\text { empregador, geralmente obrigando- } \\
\text { se ao cumprimento de uma jornada } \\
\text { de trabalho e que recebe, em } \\
\text { contrapartida, uma remuneração } \\
\text { total ou parcial em dinheiro. }\end{array}$ \\
\hline $\begin{array}{l}\text { Trabalhador } \\
\text { por conta própria }\end{array}$ & $\begin{array}{l}\text { Indivíduo que é proprietário, individual } \\
\text { ou em conjunto com outros, de unidades } \\
\text { produtivas não constituídas em } \\
\text { sociedade sem empregados. }\end{array}$ & $\begin{array}{l}\text { Pessoa que, individualmente ou com } \\
\text { auxiliares, explora uma atividade } \\
\text { econômica ou exerce uma profissão } \\
\text { ou ofício de forma permanente ou } \\
\text { eventual. }\end{array}$ \\
\hline $\begin{array}{l}\text { Empregador } \\
\text { (sócios e } \\
\text { proprietários) }\end{array}$ & $\begin{array}{l}\text { Proprietário, individuail ou em conjunto } \\
\text { com outros, de unidades produtivas não } \\
\text { constituídas em sociedade com } \\
\text { empregados remunerados. }\end{array}$ & $\begin{array}{l}\text { Pessoa que trabalha explorando o } \\
\text { seu próprio empreendimento, } \\
\text { independentemente de ser ou não } \\
\text { constituído em sociedade, tendo pelo } \\
\text { menos um empregado remunerado. }\end{array}$ \\
\hline
\end{tabular}

Fonte: Elaboração própria a partir das informaçōes de SCN/IBGE, POF/IBGE e PNAD/IBGE.

A utilização dos resultados da Rais no que se refere ao confronto dos dados de ocupação com vínculo da nova série do SCN complementou a análise e certificou a conclusão a respeito da qualidade da informação gerada pelo novo SCN. De fato, a inexpressiva diferença encontrada para a informação harmonizada de postos de trabalho entre as duas bases $(0,4 \%$ a mais no $\mathrm{SCN}$ ) comprovou a confiabilidade dos resultados do SCN também de forma desagregada.

\section{NOTAS}

1. Como exemplos podem ser citadas a reclassificação de alguns impostos, a modificação do índice de volume da administração pública, a mudança de âmbito e do índice de volume para o setor financeiro e a contabilização do número de ocupações em vez de pessoas ocupadas para a mensuração do fator trabalho. Detalhes sobre as revisões específicas na nova série do SCN encontram-se nas 25 notas metodológicas disponíveis no 
site do IBGE: http://www.ibge.gov.br/home/estatistica/economia/contasnacionais/referencia2000/2005/default_SCN.shtm

2. Para os propósitos deste trabalho, a série referente a esse período será denominada série antiga.

3. A comparação entre os resultados das séries nova e antiga de contas nacionais encontrase na nota metodológica no 24: Tabelas comparativas (IBGE, 2007).

4. Para detalhamento da metodologia adotada na construção da antiga série, ver: IBGE (2004).

5. Para os anos 1991, 1994 e 2000, em que não houve PNAD, fez-se uso de índices alternativos (como os originados pela Pesquisa Mensal do Emprego) e de procedimentos de interpolação para a obtenção dos resultados.

6. Mais detalhes ver: IBGE (2006). Nota metodológica n 7: Rendimento do trabalho e ocupação.

7. A PNAD também contabiliza o número de pessoas que possuem três ou mais trabalhos. No entanto, optou-se por não incluir essa variável na nova série devido à impossibilidade de identificar a atividade econômica da ocupação. Ademais, as pessoas que exercem um terceiro trabalho têm, historicamente, um peso muito pouco expressivo sobre o total $(0,4 \%)$.

8. Com a reformulação do sistema estatístico nacional, o IBGE encerrou os Censos Econômicos (o último ocorreu em 1985) e adotou as pesquisas econômicas: Pesquisa Industrial Anual (PIA), Pesquisa Anual de Serviços (PAS), Pesquisa Anual do Comércio (PAC) e Pesquisa Anual da Indústria da Construção (PAIC).

9. Para atividades de educação, saúde e administração públicas, serviços prestados principalmente às famílias e serviços, domésticos, a fonte é a PNAD; para as de intermediação financeira, seguros, previdência complementar e planos de saúde, pesquisa e desenvolvimento, saúde mercantil, atividades associativas, educação mercantil e eletricidade e gás, a base de dados é o Cempre, sendo a Aneel a fonte específica para o cálculo da remuneração da atividade produção e distribuição de energia elétrica.

10. No Sistema de Contas Nacionais, as unidades institucionais são organizados em cinco grandes setores: empresas não financeiras, empresas financeiras, instituições sem fins de lucro a serviço da família, administrações públicas e famílias. Os quatro primeiros setores institucionais são compostos por entidades jurídicas ou sociais específicas cuja existência é reconhecida pela lei. O SNA-93 define família como um pequeno grupo de indivíduos que partilham o mesmo domicílio e reúnem parte, ou a totalidade, do seu rendimento e patrimônio, consumindo coletivamente certos tipos de bens e serviços, principalmente de habitação e alimentação. Os empregadores informais são os proprietários de unidades produtivas não registradas formalmente.

11. Entendem-se como rendimento misto os ganhos recebidos pelos titulares de empresas não constituídas em sociedade pertencentes às famílias (ONU, 2007, p. 7.31). A denominação "misto" é devida à natureza do ganho do trabalhador, que não pode ser especificada como rendimento do trabalho ou do capital. 
12. Segundo a PNAD, em 2003, o percentual de pessoas que possuíam mais de um trabalho correspondeu a aproximadamente $4 \%$.

13. A DIPJ não é uma fonte adequada para a análise dos dados de rendimento, uma vez que tais informações não são investigadas para uma série de empresas, já que estas não respondem ao formulário de Lucro Real — o mais completo no fornecimento das informações. Ademais, os rendimentos de alguns setores de atividade, como a agropecuária e a administração pública, também não são corretamente captados por essa fonte. Uma outra variável que não é contemplada é o auxílio-transporte, componente do salário não monetário.

14. A anualização do rendimento consiste na aplicação de um fator para transformar a estimativa de rendimento do mês de referência na de rendimento anual.

15. As informações da própria PNAD a partir de 2005 , quando essa área já fora contemplada pela pesquisa, atestam essa conclusão. Por exemplo, o peso das áreas rurais da região Norte na renda total das famílias é inferior a 1,0\%.

16. Na PNAD de 2003, esse período correspondeu à semana de 21 a 27 de setembro daquele ano.

17. No conceito de trabalho, caracterizam-se as condições de trabalho remunerado e não remunerado bem como de trabalho na produção para próprio consumo ou na construção para o próprio uso.

18. Para mais detalhes, ver: IBGE (2006).

19. Para mais detalhes, ver: IBGE (2006).

20. A mesma conclusão é válida para a POF, cujos resultados são apresentados na próxima seção. Um quadro comparativo com essas diferenças conceituais entre o SCN e as pesquisas domiciliares encontra-se no Anexo.

21. O dado reforça a impressão acerca da subestimação da população ocupada, acompanhada pela massa de rendimento na série de 1985 do SCN. Especificamente sobre a questão dos rendimentos na série antiga, ver Barros et al. (2007).

22. A massa salarial divulgada no SCN 2000 acusou variação de 32,1\% em face da registrada na série antiga, conforme dados da tabela 1.

23. Um dos motivos seria a não-resposta ou a subdeclaração dos rendimentos das classes de renda mais alta. Outra questão diz respeito à tendência do informante em responder o rendimento líquido e não o bruto (Rocha, 2002, p. 7).

24. A POF combina o período de coleta de 12 meses com períodos de referência de até 12 meses, para alguns itens bem como rendimentos. Logo, as informações estão distribuídas em um período de 24 meses, o que requer que os valores levantados pela pesquisa sejam valorados a preços de uma data referencial.

25. Conforme informado, a PNAD não trata dos rendimentos monetários eventuais, tais como horas extras, participação nos lucros, indenizações trabalhistas, e nem considera alguns benefícios (auxílio-transporte, auxílio-refeição, entre outros).

26. O conteúdo completo das variáveis e a forma de preenchimento do formulário da Rais encontram-se em seu Manual de Orientação: MTE (2005). 
27. Enquanto o emprego no comércio se expande nos últimos meses do ano, normalmente a indústria apresenta um comportamento compensatório devido ao menor dinamismo com o fim das encomendas para o Natal.

28. É oportuno ressaltar que não houve estimação de sócios e proprietários para as atividades de administração pública e serviços industriais de utilidade pública, por não fazer sentido esse tipo de ocupação, e para a agropecuária, devido à inexistência de informação.

\section{REFERÊNCIAS BIBLIOGRÁFICAS}

BARROS, R. P. de; CURY, S.; ULYSSEA, G. A desigualdade de renda no Brasil encontra-se subestimada? Uma análise comparativa com base na PNAD, na POF e nas contas nacionais. Texto para Discussão, Rio de Janeiro: IPEA, n. 1263, 2007.

IBGE Pesquisa Nacional por Amostra de Domicílios. Rio de Janeiro, 2003. v. 24.

IBGE Pesquisa de Orçamentos familiares 2002-2003: primeiros resultados, Brasil e grandes regiões. 2. ed. Rio de Janeiro: IBGE, 2004.

IBGE Sistema de Contas Nacionais do Brasil. Rio de Janeiro: IBGE, 2004. (Série Relatórios Metodológicos, v. 24.)

IBGE Sistema de Contas Nacionais, Brasil, referência 2000. Rio de Janeiro: IBGE, 2007. (Nota metodológica n. 24: tabelas comparativas.)

IBGE Sistema de Contas Nacionais, Brasil, referência 2000. Rio de Janeiro: IBGE, 2006. (Nota metodológica n. 7: Rendimento do trabalho e ocupação.)

MTE. Manual de orientação da Relação Anual de Informações Sociais - Rais, ano base 2003.

ONU (2007). System of National Accounts 1993 [SNA-93]. Rev. 4. Nova York: United Nations. Disponível em: http://unstats.un.org/unsd/sna1993/introduction.asp

ROCHA, S. A Investigação do rendimento na PNAD: comentários e sugestões à pesquisa nos anos 2000. Texto para Discussão, Rio de Janeiro: IPEA, n. 899, 2002. 